\title{
Autologous Platelet-Rich Stroma in Complex Perianal Fistulas
}

\author{
Wouter Deijl, M.D. ${ }^{1}$ 'Jeanine Arkenbosch, M.D. ${ }^{2}$ Oddeke van Ruler, M.D., Ph.D. ${ }^{1}$ \\ C. Janneke van der Woude, M.D., Ph.D. ${ }^{2}$ Hieronymus P. J. D. Stevens, M.D., Ph.D. ${ }^{3}$ \\ Eelco de Graaf, M.D., Ph.D. ${ }^{1}$ Ruud Schouten, M.D., Ph.D. ${ }^{1}$ \\ 1 Department of Surgery, IJsselland Hospital, Capelle aan den IJssel, The Netherlands \\ 2 Department of Gastroenterology, Erasmus Medical Center, Rotterdam, The Netherlands \\ 3 Department of Plastic Surgery, Velthuis Clinic, Rotterdam, The Netherlands
}

$\mathrm{R}$ egardless of surgical technique, success rates of reconstructive surgery in patients with complex perianal fistulas are limited, and fistula often reoccur. ${ }^{1}$ One of the theories on failure is the presence of persistent chronic inflammation in the fistula tract residue, decreasing the impact of factors promoting tissue repair. ${ }^{2}$ Consequently, suppletion of these factors could increase the success rate.

Recent efforts to improve postoperative healing focus on the enhancement of the regenerative potency of wound tissues. Stromal vascular fraction (SVF) produces growth factors promoting mitosis and enhancing the regenerative capacity of the cells, promoting wound healing. ${ }^{3}$ Plateletrich plasma (PRP) contains a high concentration of platelets, which excrete growth factors such as platelet derived growth factor. ${ }^{3}$ From a wound healing perspective, SVF is potent because the extracellular matrix can increase tissue regeneration and augment reperfusion attributed to present microvasculature. In combination with PRP, it forms platelet-rich stroma (PRS). So far, only the use of either allogeneic PRP or enzymatically prepared SVF for the enhancement of healing in perianal fistulas is described. ${ }^{4,5}$

However, in normal homeostasis, PRP and SVF are inextricably linked, explaining the limited impact

Funding/Support: None reported.

Financial Disclosure: None reported.

Presented at the meeting of the European Society of Coloproctology, Nice, France, September 26 to 28, 2018, and the abstract from that presentation was published. ${ }^{6}$

Correspondence: Wouter Deijl, M.D., IJsselland Hospital, Prins Constantijnweg 2, Capelle aan den IJssel, 2906 ZC, The Netherlands. E-mail: wouterdeijl@gmail.com

Dis Colon Rectum 2020; 63: 860-861

DOI: 10.1097/DCR.0000000000001546

(C) The ASCRS 2019 described so far. Moreover, only allogeneic products are used with their procedural and immunologic disadvantages. In this video, we describe the combined perioperative mechanical capture and use of both autologous PRP and autologous SVF in a patient who underwent a transanal mucosal advancement flap repair for a complex transsphincteric perianal fistula. First, lipoaspirate was harvested and centrifuged to isolate dehydrated adipose tissue. This dehydrated adipose tissue was subsequently fractionated and centrifuged again to obtain autologous SVF. Concomitantly, autologous PRP was obtained through centrifugation of a venous blood sample. Autologous PRS was created by merging autologous PRP and SVF. PRS was injected along the fistula tract before suturing of the advancement plasty. This video illustrates the technical aspect of successful conduction of this operation. See Video at http://links.lww.com/DCR/B85.

KEY WORDS: Colorectal surgery; Growth factors; Perianal fistula; Platelet-rich stroma; Stromal vascular fraction; Transanal mucosal advancement flap plasty.

\section{REFERENCES}

1. Malik AI, Nelson RL. Surgical management of anal fistulae: a systematic review. Colorectal Dis. 2008;10:420-430.

2. Mitalas LE, Gosselink MP, Zimmerman DD, Schouten WR. Repeat transanal advancement flap repair: impact on the overall healing rate of high transsphincteric fistulas and on fecal continence. Dis Colon Rectum. 2007;50:1508-1511.

3. Lin G, Garcia M, Ning H, et al. Defining stem and progenitor cells within adipose tissue. Stem Cells Dev. 2008;17: 1053-1063.

4. van Koperen PJ, Wind J, Bemelman WA, Bakx R, Reitsma JB, Slors JF. Long-term functional outcome and risk factors for recurrence after surgical treatment for low and high perianal fistulas of cryptoglandular origin. Dis Colon Rectum. 2008;51:1475-1481. 
5. van der Hagen SJ, Baeten CG, Soeters PB, van Gemert WG Autologous platelet-derived growth factors (platelet-rich plasma) as an adjunct to mucosal advancement flap in high cryptoglandular perianal fistulae: a pilot study. Colorectal Dis. 2011;13:215-218.
6. Deijl WB, van Ruler O, van der Woude J, Stevens J, de Graaf EJR, Schouten WR. V10: additional injection of autologous platelet rich stroma in transanal advancement flap repair of high transsphincteric fistulas. Colorectal Dis. 2018;20:144-145.

\section{New Responsive Design website optimized for mobile devices}

\section{Fuel Your Professional Growth at dcrjournal.com}

Diseases of the Colon \& Rectum has a new responsive design website that delivers an optimal reading experience on any mobile device - no app required! Access $\boldsymbol{D C} \boldsymbol{R}$ journal content on the go, plus these features:

- Podcasts

- Clinical Practice Guidelines Collection

- Visual Abstract Infographics

- Tips for Submitting to DC\&R

- Video Introduction to each Issue from the Editor-in-Chief

- Video Abstracts and Video Vignettes

- Entire Archive of DC\&R content back to 1958

- Links to Residents Corner and CME

- Legislative updates

\section{Visit dcrjournal.com today.}

Access is a subscriber and ASCRS member benefit.

\section{Wolters Kluwer}

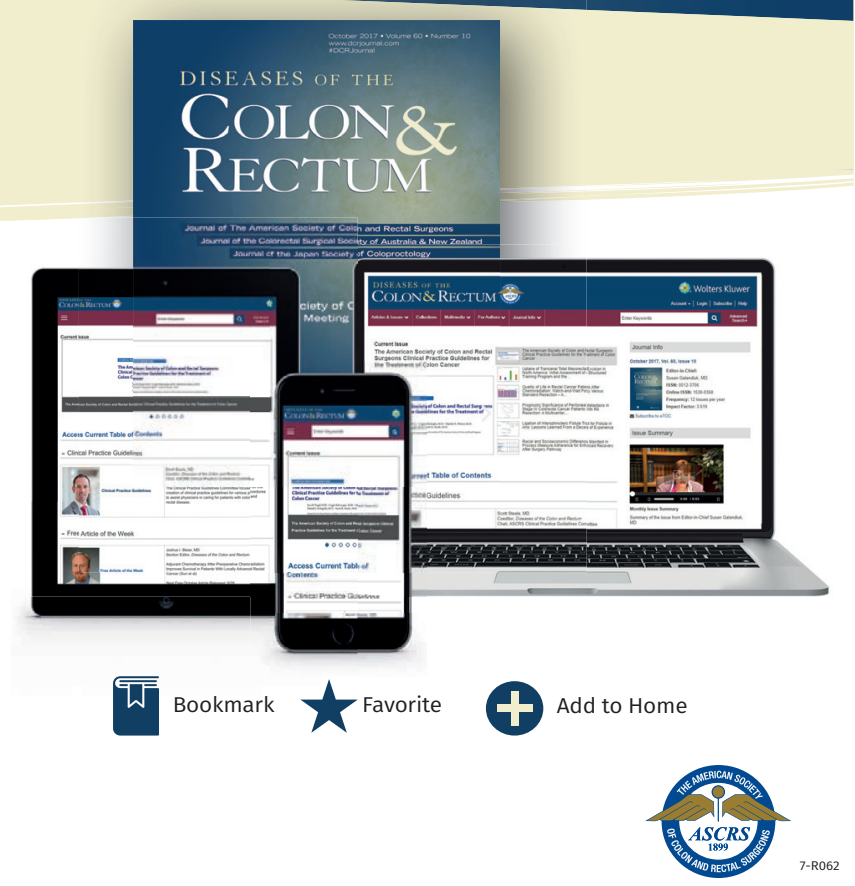

